\title{
Role of the Professional Body in a Pandemic
}

\author{
Lesley Arnold, Zaffar Sadiq Mohamed-Ghouse and Tony Wheeler
}

Surveying and spatial sciences professional bodies are highly conscious of the impact that the novel coronavirus COVID-19 is having on Members and sustaining partners. This awareness has seen member services and activities repackaged across the globe accordingly. This chapter gives an Australian perspective of the role of the professional body during the pandemic: from ensuring the continued availability of professional development events, advocating on behalf of Members and industry, and maintaining professional networking opportunities.

\subsection{Introduction}

The COVID-19 pandemic has created a public health emergency that has had a massive impact on society and economies worldwide. Almost everyone is being impacted in some way by the unprecedented enforced business closures, border lockdowns and social distancing measures enacted to reduce the spread of the virus.

This disruption has, and continues to have, an impact on professional bodies and their members. Members are faced with the fear of unemployment, having to come to grips with home schooling and social isolation, sifting through misinformation to stay on top of evolving pandemic-related policy and regulations, and confronting a new way of life where health concerns and the wellbeing of family are the highest priority.

Understanding how the professional body can provide value during these unprecedented times is not clear cut. Like governments and businesses, the Surveying and Spatial Sciences Institute (SSSI) Australia, is grappling with the question 'What are the impacts and consequences of the COVID-19 pandemic on our members and industry?' - and, as a voice for our members, 'What are some of the services and solutions we can offer Members to boost opportunities for continued learning, networking and career development - in a time when job security, financial markets and economies are so uncertain'?

To answer these questions, SSSI conducted a COVID-19 Member Survey in April 2020 to gauge Member concerns and understand their needs. The responses received were encouraging - SSSI was on the right track, but with scope for improvement in six areas explained in this Chapter, namely:

1. Advocacy: Advocate on behalf of the surveying and spatial sciences as an essential service during the pandemic.

2. CPD: Continue to provide opportunities for Continuing Professional Development (CDP) but in an online format across all disciplines - surveying, hydrographic, engineering and mine surveying, spatial information and cartography, and remote sensing and photogrammetry.

3. Member Connect: Provide opportunities for Members to connect including channels where 
they can seek support and advice on professional matters from other Members, while working from home environments.

4. Job Opportunities: A National 'Jobs Board' and support for curriculum vitae/resume writing.

5. Member Services: Adapt member processes to align with COVID-19 restrictions, such as removing the need for face-to-face communications.

6. Economic Sensitivity: Review the cost of services and hardship guidelines to align with economic uncertainties faced by Members.

For many Associations [1], the COVID-19 pandemic has created more work. Keeping members up-to-date with information updates, increased advocacy on behalf of members (including liaison with government, industry and other associations), moving professional development and member meetings online, and increasing webinar and digital content production, has had a substantial impact on workloads. According to the COVID-19 Impact Survey 'Finding Opportunity in Crisis' conducted by the Australian Society of Association Executives (AuSAE), 'through this disruption, associations have been working tirelessly to collect, curate and disseminate information, advocate to government to assist in the formation and impact of policy, and provided support and assistance for the professions and industries they represent'.

This Chapter discusses the role of the Surveying and Spatial Sciences Institute (SSSI), Australia during the COVID-19 pandemic. Results from the COVID-19 Member Survey are discussed, along with how the Institute is responding to Member feedback.

The lessons learned have application to similar industry associations and professional bodies, looking for ways to respond to Member's needs during these extraordinary times, as well as providing pathways for Members to apply their unique surveying and spatial sciences skillsets to help communities better manage infectious disease outbreaks.

\subsection{Serving Surveying and Spatial Science Professionals}

The Surveying and Spatial Sciences Institute (SSSI) is Australia's peak body representing the interests of surveying and spatial science professionals. SSSI combines the disciplines of land surveying, engineering and mining surveying, cartography, hydrography, remote sensing and spatial information science.

SSSI Members work in diverse roles across various sectors (health, transport, energy, planning, security, resources, education, property, etc.) including academia, government and private businesses throughout Australia and New Zealand, as well as overseas nations.

SSSI gives a voice to Members of the surveying and spatial sciences community, building upon the traditions, values and history of the surveying and spatial sciences profession, as well as fostering and empowering Members to achieve excellence and make positive contributions to the global community through learning programs that showcase innovative technological developments in both the national and international arena. SSSI recognises and showcases the excellence achieved by surveying and spatial sciences practitioners and the significant contributions they make to the wellbeing of communities.

While SSSI conducts ongoing reviews of Members services, the challenges posed to Members and developments in the profession itself have been fast-paced during the pandemic. One of the biggest impacts by far, has been the lockdown restrictions as these have prevented face-to-face meetings, Continuing Professional Development (CPD) events, and networking opportunities. These challenges are not unique to SSSI. The International Federation of Surveyors ${ }^{1}$ (FIG) notes

\footnotetext{
${ }^{1}$ International Federation of Surveyors (FIG) a United Nations and World Bank recognised non-governmental organisation of national member associations, cadastral and mapping agencies and ministries, universities and corporates from over 120 countries
} 
significant developments in surveying professional education due to the COVID-19 restrictions and the need to adapt to online learning and teaching. According to Associate Professor David Mitchell, Chair of FIG Commission 2 FIG, this has presented a range of challenges including which learning management system and video communications platforms to use, how to reach those students without adequate internet connection or with poor ICT quality, and how to teach those tasks that are heavily based around face-to-face contact, such as practical field projects, computer lab sessions and cartographic design projects. The result of these considerations has revealed some valuable lessons for blended learning opportunities [2].

\subsection{COVID-19 Member Survey}

To better understand how Members are faring during the COVID-19 Pandemic, SSSI issued a survey early April 2020 to Members asking them how SSSI can support their professional needs during this difficult time. There were seven questions. The results are summarised below and addressed in the following sections:

1. Are you currently concerned about achieving your CPD points to maintain your professional and/or certified status? (50\% No; $38 \%$ Yes; and 12\% Undecided)

2. What type of CPD are you most interested in participating in? Respondents could choose more than one option. (67\% Surveying; 47\% Geospatial; 28\% Data Science; 27\% Business Practices; $14 \%$ Project Reviews; and 39\% Soft Skills)

3. Are you aware that SSSI offers a program of online live webinars and recorded eCPD events, to assist you to maintain CPD? (92\% answered Yes; and $8 \%$ answered No)

4. Have you participated in a SSSI webinar? (19\% answered No; and $44 \%$ answered Yes)

5. What has prevented you from participating? (19\% said topic was not of interest; $34 \%$ said time not convenient; $22 \%$ said the cost was too high; $8 \%$ were not comfortable with the technology; and $41 \%$ said they did not have the time)

6. How has COVID-19 impacted your work life? (3\% Made redundant; $16 \%$ Work hours reduced; $5 \%$ partner/spouse made redundant; $48 \%$ Working as normal; $42 \%$ Working as normal but from home; $13 \%$ Juggling work and home schooling; $15 \%$ Other - e.g. retired)

7. Are you interested in participating in online social events with other surveying and spatial professionals, for example afternoon virtual drinks, online quiz nights? (36\% answered Yes; and $66 \%$ answered No)

The survey was completed by 362 Members. This low response rate told its own story - that Members were faced with other more pressing issues during the onset of the pandemic.

Nonetheless, the results were revealing and the feedback has helped SSSI respond differently in terms of advocacy, CPD, Member Connect (networking), job prospects, member services, financial sensitivities and volunteer opportunities.

\subsubsection{Advocacy}

SSSI has been encouraging growth and increasing the level of the understanding of the surveying and spatial profession across allied professions and the wider community over many years. This is typically done through incentives to support education in schools, informative articles, blogs and white papers on topics of critical relevance to the industry, as well as building the relevance of 
surveying and spatial sciences in government policy and, more recently facilitating online panel discussions.

In recent years, the focus for SSSI has been advocating on Australia's Services Export Plan [3], 2026 Spatial Industry Transformation and Growth Agenda [4], Diversity and Inclusion [5], Asia Pacific Capacity Development [6], Square Kilometre Array [7], mentoring for young professionals [8], geospatial in schools [9], Australia's Decadal Plan for Geography [10], and Australia's Spatial and Space Road Map, and so forth.

With the COVID-19 Pandemic, policy positions are evolving rapidly, and SSSI is now advocating alongside other industry associations - calling on all Australian Governments to ensure that responses to COVID-19 include dedicated strategies and take all necessary measures to protect and support people.

SSSI is also helping our professionals to be heard - advocating for surveying to be classified as an essential service for the community during the pandemic. Hydrographic surveyors are essential to maintaining the safety of our ports, engineering and mine surveyors are crucial to mining operations, and cadastral surveyors are essential to construction projects. All these services have ramped up as the government increases mining and construction to buoy up the economy. GIS professionals have also been busier than usual, particularly in the health sector where the crucial need for mapping services, COVID-19 dashboards and spatial analysis have increased as outbreaks have escalated. And yet, surveying and professionals are struggling to meet higher than usual demands due COVID-19 restrictions, for example:

- Surveyors costs have increased due to survey teams travelling in individual vehicles to worksites to maintain social distancing.

- Intrastate border lockdowns, such as those between regions in Western Australia, have prevented surveyors travelling to worksites, as travel permits only apply to recognised essential services.

- Engineering and Mine Surveyors are struggling to get to mine sites, because of the lack of local flights and restrictions on seating allocations.

While the methods of advocacy remain largely the same (policy statements, newsletters, telephone communications, opinion pieces) during the pandemic, the topics have undergone a considerable change - creating new 'advocacy territory' for SSSI and likeminded organisations. With this new environment, brings the need to engage more often with Members in order to respond on their behalf and in a time-sensitive manner.

\subsubsection{Continuing Professional Development}

SSSI offers members a Continuing Professional Development (CPD) Program designed to complement the busy professional wishing to undertake activities to further their current skills and experience within the workplace.

Given the cancellation of face-to-face events to comply with social distancing measures, it was surprising that the majority of survey respondents were not concerned about achieving their CPD accreditation for the year. Their optimism was buoyed by the increase in webinars and the ability to participate in monthly CPD meetings online.

As the COVID-19 outbreak unfolded, the ability to respond quickly with online CPD webinars was enabled through the support of Member volunteers, government, private industry and regional associations. SSSI held regular communications with cooperating regional associations - ASEAN Federation of Land Surveying and Geomatics ${ }^{2}$ (AFLAG), Pacific Geospatial and Surveying Council $^{3}$ (PGSC) and Surveying \& Spatial New Zealand ${ }^{4}$ (S+SNZ). The outcome of these

\footnotetext{
${ }^{2}$ ASEAN Federation of Land Surveying and Geomatics (AFLAG), is the professional association duly accredited by the ASEAN Secretariat based in Jakarta, Indonesia representing the Geodetic Engineers, Surveyors and Geomatics practitioners in the region).

${ }^{3}$ Pacific Geospatial and Surveying Council (PGSC) vision is to focus on sustainable development in the Pacific Islands region enabled by world-class geospatial information and surveying services.

${ }^{4}$ Surveying \& Spatial New Zealand $(\mathrm{S}+\mathrm{SNZ})$ is the professional body representing survey and spatial
} 
discussions was the addition of jointly supported online events to provide mutual CPD opportunities for members of respective organisations.

The SSSI has been proactive in establishing Memorandums of Understandings (MOUs) and reciprocating arrangements with several likeminded professional associations and not for profit organisations including Open Geospatial Consortium ${ }^{5}$ (OGC), Urban and Regional Information Systems Association ${ }^{6}$ (URISA), FIG and International Society for Photogrammetry and Remote Sensing (ISPRS). These collaborations are proving crucial during the pandemic, particularly as the appetite for learning programs has increased, as they foster shared resourcing opportunities and knowledge-sharing. Collaboration is ongoing, and there has been a high-degree of information sharing through online panel discussions, to explore mutually beneficial opportunities for Members. The SSSI continues to monitor webinar activities globally for relevant content and opportunities for Members, and conversely, is also recording attendance levels to see if webinar fatigue sets in, to see if other opportunities need to be considered.

\subsubsection{Member Connect}

One of the primary roles of a professional body is enabling networking opportunities for members, locally, nationally and internationally. SSSI supports a network of strategic partners across all levels of government, Not-for-profit (NFP) and the private sector. The aim is to proliferate influence and broaden the support base to increase the reach and benefits for the membership.

Before the pandemic, SSSI provided a dedicated series of network building opportunities. For many Members this network helps to build careers, stay connected with peers, and to share experiences and learn from each other. At the local level, the regional committees customise networking events that have local interest to Members; at a National level, events are coordinated by the National Events Manager, and international events are typically organised through a steering committee, made up of interested parties.

With face-to-face events cancelled, SSSI has had to find creative ways to enable Members to connect. For example, the Locate 20 conference was reinvented as Locate Connect $^{7}-$ a virtual series bringing experts together to present on location-based topics and contribute to Q\&A panel sessions.

While socialising has been difficult during the pandemic, survey respondents indicated that they were not especially looking for virtual social events from their professional body. People cited being 'time poor' as the main drawback, while others noted they happy to wait for face-to-face socialising to return.

Nonetheless, amidst the COVID-19 pandemic, SSSI went virtual for the annual Oceanic Asia-Pacific Spatial Excellence Awards (APSEA), held 28 May 2020. These awards recognise the achievements of enterprises and individuals in the surveying and spatial sciences industry. While it wasn't the gala dinner evening that Members are accustomed to, it still provided the opportunity to congratulate those that have contributed extensively to the four pillars of the profession - academia, government, research and the private sector. APSEA has been a highlight for 2020 and given the industry an opportunity to celebrate excellence.

The SSSI adopted a ChatApp to enable participants of the Bushfire recovery Map-a-thon ${ }^{8}$ to connect. The App was rated a huge success, as it brought people together to share knowledge and ask questions of those who understand surveying and spatial sciences matter. At one point during the map-a-thon, there were over 200 participants logged in to the chat channel. It was an ideal way for the Map-a-thon community to network with each other and not feel isolated when working

professionals who work collaboratively to strengthen and celebrate the knowledge, capability and innovation within this exciting sector for the benefit of society.

${ }^{5}$ Open Geospatial Consortium (OGC) Global Resource for Information and Standards.

${ }^{6}$ Urban and Regional Information Systems Association (URISA) a non-profit association that provides education and training, a vibrant and connected community, advocacy for geospatial challenges and issues, and essential resources for GIS professionals throughout their careers.

${ }^{7}$ Locate Connect is a program of Locate Conferences Australia which SSSI is $50 \%$ shareholder and contributor https://www. locateconference.com/2021/locate-connect-program/

${ }^{8}$ OpenStreetMap is a collaborative project to create a free editable map of the world, accessible at https: //wiki.openstreetmap.org/wiki/Mapathon 
from home locations. In addition, organisers could make announcements to assist mappers, and supporters, such as Nearmap and OpenStreetMap (OSM), were able to participate and solve any technical issues immediately. Even after the map-a-thon, participants were still engaging on the chat channel, and it was exciting to see our international participants log-in during the day to get feedback before they started mapping.

SSSI is currently testing the method to enable professionals to keep in-touch during pandemic. The Chat channel includes conversations to share information on (1) spatial technologies being used to Tackle COVID-19; (2) privacy and sensitivity issues around data usage, particularly for contact tracing Apps; (3) impacts to business resulting from lockdowns and social distancing requirements; and (4) general announcements about events and Webinars.

\subsubsection{Job Prospects}

A common thread among survey respondents was the future of the profession, job prospects, and support for job seekers. Currently, SSSIs provides services that enable Members to maintain professional industry standards. This is achieved through certification programs that are relevant to current and emerging industry requirements. The certification essentially recognises that a person has demonstrated that he or she has the necessary knowledge and experience to competently work in their area of expertise.

Government organisations are increasingly adding certification as a criterion for businesses responding to tenders. This is because certification affords insurance of currency and knowledge. Since the COVID-19 outbreak there has been increased interest from regional associations to leverage these internationally accredited certification processes locally to increase job prospects for their Members. SSSI is also the authorised assessing authority for surveying and spatial sciences professionals emigrating to Australia. This experience of Migration Skills Assessment could be utilised by other countries to setup a similar process in their region and train assessors.

As a consequence of the pandemic, Members are now faced with work redundancies and the need to upskill to find new opportunities. The pandemic has highlighted that SSSI has a broader role in assisting Members to be 'Job Ready'. In addition, to CPD and certification to enhance career progression, survey respondents are keen to have support for professional curriculum vitae/resume writing, and notifications of job openings and scholarship opportunities in the surveying and spatial sciences field. Job application writing, interview training, presentation skills and a 'jobs board' are new areas for the SSSI to focus on.

\subsubsection{Member Services}

Magazines, journals and bulletins provide the most effective method for keeping Members up-to-date. The majority of these communiques are now online. However, for SSSI, some processes were still tied to the postal service and that created some concern due to delayed services, brought about by the increase postal traffic during the pandemic as people moved to online shopping delivery. For this reason, newsletters and renewal notifications were moved to online/email-only transactions. Members have been quick to approve the change - noting a reduced environmental footprint.

COVID-19 has resulted in several process improvements. To become a Member, applicants were required to meet a Justice of the Peace in person to have original academic records certified. Due to social distancing requirements, this requirement has been removed and the process to become a Member is now far more streamlined.

Cash payments for renewals are also no longer acceptable to Members during the pandemic. As a result, SSSI had to fast-track more flexible payment options for events, professional certification, membership renewals and re-joining fees - with BPay, PayPal and credit card options now available to Members in addition to the existing cheque and Electronic Funds Transfer (EFT).

SSSI regional committees also had to rethink how they engaged with Members and provided services. The SSSI Board, regional committees, and other interest groups moved to online platforms to continue their important work and socialise.

The pandemic has also fast-tracked the need to consider other process improvements, such as 
speaking with businesses and surveyors' boards to better understand the pain points for Members and employers alike. According to [11], now is the time to reimagine business models, confront challenges and position for future opportunities; this includes recovering revenue, rebuilding operations, rethinking the organisation and accelerating the adoption of digital solutions.

\subsubsection{Economic Sensitivity}

Both associations and Members are facing economic setbacks during the pandemic, and this is posing a conundrum. The cancellation of conferences and face-to-face events has removed an income stream for Professional bodies, and this revenue is required to keep Member fees down. Yet, increasing Member fees is not a palatable option. Members are also facing hardship due to reduced household incomes resulting from redundancies. This poses a dilemma for the professional body faced with having to spend additional resources (without receiving additional revenue) to be able to provide new services.

Professional bodies survive by being able to achieve sustainable 'economies of scale'. As the number of Members increase, services become more cost effective, for example the unit cost of printing a publication is reduced as the number of copies increases. This means that retaining Members and increasing Member numbers has a direct effect on the number and quality services offered, and the price-point for Members.

Interestingly, the AuSEA noted that 'Through this crisis Associations have reported increased member engagement and in some cases growth in membership as they became a trusted source of truth for their members and communities' [1].

However, the question remains, 'what can the Professional Body do to address the current economic sensitives brought on by the pandemic'?

SSSI Members are our most important asset, and providing 'value for money' to Members has never been more crucial than during the pandemic. The new financial year provided the opportunity to consider new member services, renewal options and renewal incentives.

SSSI introduced the MemberOne Program, essentially an incentive scheme for existing members to introduce new members to SSSI. The more members referred, the greater discount the Member receives to their SSSI membership fee - a substantial saving during these uncertain times. The program outline is as follows:

- Introduce one new person that becomes a financial member during $20 / 21 \mathrm{FY}$ and receive $20 \%$ discount off your membership fee in $21 / 22 \mathrm{FY}$.

- Introduce two new people that become financial members during $20 / 21 \mathrm{FY}$ and receive $25 \%$ discount off your membership fee in $21 / 22 \mathrm{FY}$.

- Introduce three new people that become financial members during $20 / 21 \mathrm{FY}$ and receive $30 \%$ discount off your membership fee in $21 / 22 \mathrm{FY}$.

In addition, SSSI has introduced monthly payment options to assist those facing hardship. Members can choose to pay monthly instead of paying an annual upfront fee. Also, SSSI has reviewed the Membership Policy to ensure the guidelines for hardship applications are applicable to pandemic situations and are simplified so as not to exacerbate the circumstances generating the hardship. While it is not possible to list all the possible circumstances, the 'Hardship Application' exempts annual subscriptions for:

- extended illness that results in a member being on extended sick leave from their work place; and

- a period of extended unemployment.

From 1 July 2020, SSSI made all webinars free to Members. This action was in response to Members' survey feedback. SSSI Webinars offer value for money when considered part of Membership fees. In addition, when SSSI does return to face to face events, that aim is to ensure that event pricing is reflective of a significant financial advantage to SSSI members over non-members. This will be important, as the financial impacts of the pandemic are expected to last for some time to come. 


\subsection{Moving Back to Normality}

There is a general perception that there is no returning to normal after COVID-19, but professional bodies do need a pathway forward. The world is likely to recover at differing speeds, and the speed will vary depending on the type of industry.

Professional bodies require a strategic decision-making framework that is a staged approach to assessing needs and priorities - one that looks beyond the current disruptions to reposition Member services to suit a post-pandemic society. This is the next big challenge for the professional body.

The pandemic affords the opportunity to step back and reposition Member services so that when life starts to get back to normal, whatever this may look like, there are new initiatives, hopes and opportunities for Members to look forward to.

\subsection{Conclusion}

During a pandemic, the professional body has an important role to play in supporting its Members and the profession it represents. This paper has presented a case study of the challenges faced by the Surveying and Spatial Science Institute (SSSI) Australia, and its Members. Through the COVID-19 Membership Survey, SSSI has been progressively responding to Members suggestions and concerns in the areas of advocacy, CPD, Member connect, Job Prospects, Member services, economic sensitivity, and opportunities for volunteering.

The next big challenge for the professional body is to look beyond the COVID-19 disruptions, and reposition Member services to suit a post-pandemic society. This will require a strategic and staged approach to implementation, and consideration of the lessons learned during the pandemic. In summary, the major lessons learned have been to:

- Vastly increase the amount of content that Members can access online, including an ambitious plan for online CPD and learning, that has since been well publicised, recognised and respected. The current climate has provided an opportunity for some Members to upskill, progress qualifications and learn new skills such as programming and latest software developments. For those Members that are 'time poor' content is available and can be downloaded after the live events.

- Establishing strong networks with other likeminded associations and organisations. The opportunity to think globally and act locally, by leveraging national and international exclusive partner agreements, has enabled SSSI to provide members with the best possible content for them to improve and grow their knowledge and competitive edge.

- Adopt a mindset of 'process improvement'. During the COVID-19 pandemic, SSSI took the opportunity to streamline processes across the business, particularly around membership applications, renewals and flexible payment options, as well as removing the need for face-to-face communications - no longer appropriate during the pandemic.

- Enhance Certification Programs. SSSI, through its Engineering Mine Surveying Commission volunteers, has enhanced the Engineering and Mine Surveying Certification process - providing Members with an additional incentive to learn, and have that learning recognised.

- Maximise value for Members by opening up communication channels in times of crisis. The SSSI connected with Members via the COVD-19 Member Survey. The feedback has enabled SSSI to makes decisions that create value for money for members including free Webinars and opportunities to enhance job prospects; as well as consider the financial constraints on Members and their families during this difficult time. 


\section{References}

[1] AuSAE (Australian Society for Association Executives), 2020.

[2] David Mitchell. COVID-19 responses and FIG2020: lessons for Surveying Education, FIG Commission 2: Professional Education, 2020. URL https://fig.net/fig2020/articles/FIG2020_2_professional_education. htm.

[3] Surveying and Spatial Sciences Institute. Launch of Action Plan for Australia's Export Services, 2019. URL https://sssi.org.au/knowledge-hub/news/launch-of-action-plan-for-australia-s-export-servi.

[4] 2026 Agenda. 2026 Spatial Industry Transformation and Growth Agenda, 2019. URL https://2026agenda. $\mathrm{com} /$.

[5] 2026 Agenda. Diversity and Inclusion, 2019. URL https://2026agenda.com/diversity-and-inclusion/.

[6] Surveying and Spatial Sciences Institute. Asia Pacific Capacity Development Network, 2019. URL https: //sssi.org.au/knowledge-hub/news/asia-pacific-capacity-development-network-report.

[7] Surveying and Spatial Sciences Institute. Steps taken on SKA quest, 2019. URL https://sssi.org.au/ knowledge-hub/news/steps-taken-on-ska-quest.

[8] Surveying and Spatial Sciences Institute. National YP Mentoring Program, 2019. URL https://sssi.org.au/ sssi-community/special-interest-groups/young-professionals/national-yp-mentoring-program.

[9] Surveying and Spatial Sciences Institute. Geospatial Schools Competition - Winners Announced!, 2019. URL https://sssi.org.au/knowledge-hub/news/geospatial-schools-competition-winners-announced.

[10] Surveying and Spatial Sciences Institute. Australia's Decadal (strategic) Plan for Geography launched 22 November 2018, 2018. URL https://sssi.org.au/knowledge-hub/news/australia-s-decadal-strategic-planfor-geography.

[11] McKinsey. From surviving to thriving: Reimagining the post-COVID-19 return, $2020 . \quad$ URL https://www.mckinsey.com/featured-insights/future-of-work/from-surviving-to-thriving-reimaginingthe-post-covid-19-return\#. 
$\Longrightarrow$ Taylor \& Francis Taylor \& Francis Group

http://taylorandfrancis.com 